\title{
INFLUÊNCIA DE OBJETOS DIGITAIS DE APRENDIZAGEM NAS CONCEPÇÕES DE CONCEITOS DE ZOOLOGIA, UMA EXPERIÊNCIA EM PORTUGAL
}

\section{INFLUENCE OF DIGITAL LEARNING OBJECTS ON CONCEPTIONS OF ZOOLOGY CONCEPTS, AN EXPERIENCE IN PORTUGAL}

\author{
Elizabeth Aparecida Assis Brandão Danhão \\ Universidade Cruzeiro do Sul (profbethbrandao@gmail.com). \\ Bolsista CAPES / PSDE- 88881.189147 / 2018-01 \\ Rita de Cássia Frenedozo \\ Universidade Cruzeiro do Sul (ritafrenedozo@yahoo.com.br) \\ Juliano Schimiguel \\ Universidade Cruzeiro do Sul (schimiguel@gmail.com) \\ Ana Cristina Hurtado de Matos Coelho \\ Universidade do Algarve (acoelho@ualg.pt)
}

\section{Resumo}

Este artigo é parte de uma pesquisa de doutoramento que busca analisar a influência de objetos digitais de aprendizagem no processo educacional. A pesquisa contou com a presença de 10 (dez) alunos do primeiro semestre do curso de Biologia e Biotecnologia de um Instituto Politécnico em Portugal. Para essa análise buscamos desenvolver uma sequência metodológica com a aplicação de 03 (três) testes, desenvolvidos no Google Drive Forms, contendo 10 (dez) questões de múltipla escolha cada um. E a utilização de um objeto digital de aprendizagem, o site Planetabio, com foco nos conteúdos de Zoologia dos Invertebrados e dos Vertebrados. Os links dos testes foram disponibilizados para serem acessados pelos celulares dos alunos. Após uma semana, os alunos foram orientados a explorarem o site Planetabio, por 01 (uma) hora e na sequência responderem a um novo questionário, o $2^{\circ}$ teste. Com um intervalo de 15 (quinze) dias os alunos realizaram o $3^{\circ}$ teste. Durante todo o processo os professores só orientaram os procedimentos, ou seja, não explicaram nenhum conteúdo e nenhuma questão. Os resultados foram analisados de forma quantitativa simples e nos mostram uma pequena elevação nas quantidades de acertos entre os $1^{\circ}$ e o $2^{\circ}$ testes. Temos também um aumento na média geral da turma de 3,3 para 3,7 no segundo teste. Apesar de ser um pequeno indicio, podemos considerar uma possível influência positiva do objeto digital de aprendizagem no processo educacional, mas ainda temos que nos aprofundar em nossas pesquisas.

Palavras-chave: Objetos Digitais de Aprendizagem, Zoologia, Portugal, Planetabio.

Abstract 
This article is part of a $\mathrm{PhD}$ research that seeks to analyze the influence of digital learning objects in the educational process. The research was attended by 10 (ten) students of the first semester of the Biology and Biotechnology course of a Polytechnic Institute in Portugal. For this analysis we tried to develop a methodological sequence with the application of 03 (three) tests, developed in Google Drive Forms, containing 10 (ten) multiple choice questions each. And the use of a digital learning object, the Planetabio (in Portuguese) site, focusing on the contents of Invertebrate and Vertebrate Zoology. The test links were made available to be accessed by students' cell phones. After a week, the students were instructed to explore the Planetabio site for one (1) hour and then respond to a new questionnaire, the 2nd test. With an interval of 15 (fifteen) days the students performed the 3 rd test. Throughout the process the teachers only guided the procedures, that is, they did not explain any content and no question. The results were analyzed in a simple quantitative way and show a small increase in the correct quantities between the 1 st and 2 nd tests. We also have an increase in the overall grade point average of 3.3 to 3.7 in the second test. Although it is a small indication, we can consider a possible positive influence of the digital learning object in the educational process, but we still have to deepen in our researches.

Keywords: Digital Learning Objects, Zoology, Portugal, Planetabio.

\section{Introdução}

A tecnologia está cada vez mais presente no cotidiano das pessoas. Ela é encontrada em quase tudo, até mesmo em coisas mais simples como uma caneta. Essas tecnologias podem ser usadas para nos auxiliar em diferentes perspectivas e necessidades, como no uso doméstico, na educação e até mesmo em pesquisas científicas avançadas. A geração atual já nasceu convivendo cercado por essas tecnologias, sendo assim, é comum visualizarmos vídeos na internet de bebês utilizando celulares e tabletes com muita naturalidade.

Os adolescentes também apresentam muita facilidade na utilização de variadas tecnologias, como celulares, tabletes, notebooks, internet, aplicativos (APPs), softwares, etc., ou seja, esses instrumentos digitais já estão acoplados ao cotidiano dessa geração. Sendo assim, podemos tentar fortalecer o processo educacional, dentro e fora das escolas, através da utilização dessas tecnologias com o auxilio de objetos digitais de aprendizagem que auxiliem no estreitamento da comunicação entre conteúdos curriculares e a linguagem tecnológica utilizada por nossos alunos em seus cotidianos. Acreditamos que a facilidade de manuseio e acesso a esse mundo tecnológico dessa geração podem ser promissores no desempenho educacional. Para Kenski (2012), "a educação e tecnologias são indissociáveis" e se os professores utilizarem os objetos digitais adequados poderão contar com um auxilio no processo de ensino e aprendizagem, pois estarão inserindo a teoria com exemplos e linguagem reconhecidos pelos alunos, de uma forma mais lúdica e ilustrada.

Quando estamos desenvolvendo atividades no ensino superior, temos que ter em mente a formação de profissionais críticos, pensantes, competentes e treiná-los para que sejam capazes de resolver desafios. Pois, esses profissionais estarão atuando e 
influenciando a sociedade como um todo. Portanto, é fundamental estreitar a realidade cotidiana dos alunos com os conteúdos curriculares programados nos diferentes níveis educacionais. Baseados nisso, nos questionamos: se estreitarmos a linguagem tecnológica podemos obter melhores resultados acadêmicos? Será que os objetos digitais de aprendizagem podem influenciar e auxiliar no processo educacional? Sabendo que nossos alunos atuais possuem mais facilidade com a utilização da tecnologia. Baseados nestes questionamentos, demos início à nossa pesquisa, que busca analisar a influência de objetos digitais de aprendizagem.

\section{Fundamentação Teórica}

A tecnologia pode ser utilizada como uma ferramenta auxiliar no processo educacional. Porém, é necessário o uso correto dessas ferramentas para favorecer a autonomia e o desenvolvimento cognitivo dos alunos, como sugere Bittar (2006).

Bittar (2006) relata ainda uma resistência por parte de alguns professores que estão enraizados aos métodos tradicionais, com dificuldades de recursos e que acabam não concordando com a utilização dessas ferramentas em aula. A autora diz ainda que encontramos um déficit na introdução de recursos tecnológicos na formação de novos profissionais e professores. Porém, é importante superarmos essas barreiras e utilizarmos as ferramentas digitais no processo educacional, uma vez que, a familiaridade dos nossos alunos e a rica quantidade de conteúdos disponibilizados na internet podem ser excelentes auxiliares didáticos e pedagógicos, além de atraírem de forma benéfica a atenção dos alunos.

Sendo assim, se, no processo educacional, conseguirmos inserir a tecnologia como ferramenta auxiliar da educação, estaremos estreitando as formas de linguagens e comunicações através de exemplos e vivências presentes no cotidiano dos nossos alunos. A tecnologia é parte integrante da vida de muitas pessoas e a geração atual está inserida nessa tecnologia de forma a desconhecer como seria a vida sem sua utilização. Podemos, então, utilizar na educação, ferramentas que podem favorecer o ensino e aprendizagem e auxiliar os professores nesta missão.

Para Scheunemann e Lopes (2018), as tecnologias digitais apresentam potencialidades para auxiliar as estratégias docentes, pois facilitam o acesso à informação. Para Motta e Angotti (2011) apud Scheunemann e Lopes (2018), as tecnologias digitais possibilitam a construção e elaboração de novas estratégias, "transformando a maneira de aprender e ensinar", esses autores corroboram com o pensamento de Tedesco (2004, p. 11), defensor do pensamento que "a incorporação das novas tecnologias à educação deveria ser considerada parte de uma estratégia global de política educativa". Mas não é somente a utilização da tecnologia que vai melhorar o processo educacional, o professor precisa estar ciente que deve escolher corretamente o objeto digital de aprendizagem que vai auxiliá-lo em sua aplicação metodológica.

Para Bittar (2013) "a compreensão do funcionamento cognitivo dos alunos pode ser mais bem entendida com a utilização de um software adequado". A tecnologia está cheia de imagens, sons, figuras, símbolos, signos, etc.. 
Segundo Vygotsky (1994), o aprendizado é baseado em símbolos e significados que formam seu conhecimento sócio histórico cultural. A familiaridade com a tecnologia pode ser favorável ao ensino e aprendizagem, desde que sejam utilizadas as ferramentas adequadas, que contenham uma representatividade, com clareza de significados e objetivos. Portanto, a escolha do objeto digital de aprendizagem é fundamental para o sucesso do procedimento metodológico aplicado pelo professor através do uso de tecnologia em sala de aula.

Os objetos digitais de aprendizagem são definidos por Wiley (2001), como: "qualquer entidade, digital ou não digital, que pode ser utilizada, reutilizada ou referenciada durante 0 aprendizado apoiado pela tecnologia". Podem ser definidos ainda, segundo o mesmo autor, "como elementos de um de um novo tipo de instrução, com base em computadores" ou "como entidades digitais entregues via internet"... "significando que qualquer pessoa pode ter acesso e uso, simultaneamente a outros usuários". Para Bettio e Martins (2005) os objetos digitais devem estimular a reflexão e apresentar um propósito educacional (BETTIO; MARTINS, 2005 apud BRASIL, 2007). Sendo assim, os objetos digitais de aprendizagem são auxiliares dos professores e podem apresentar diferentes utilidades, funções, aparências, formatos e objetivos, sendo fundamental sua escolha consciente e planejada.

O Planetabio é um site interativo com conteúdos de Biologia e possui um layout claro, didático, de fácil manuseio e com conteúdos amplos de diferentes áreas da Biologia. O site possibilita que o aluno escolha o percurso que deseja, através das diferentes possibilidades e ligações entre os assuntos.

O site foi avaliado previamente e atendeu aos critérios baseados pela metodologia Learning Object Review Instrument (LORI) apresentados por Belfe Nesbit and Leacock (2003). Os autores sugerem nove critérios de avaliação dos objetos digitais, como: a qualidade de conteúdo, o alinhamento estratégico na aprendizagem, o feedback, a motivação, o design gráfico, a facilidade de navegação, a acessibilidade, a reusabilidade e 0 atendimento às normas e especificações internacionais.

\section{Metodologia}

O objetivo dessa pesquisa é analisar a influência de um objeto digital de aprendizagem no processo educacional de Zoologia através de uma metodologia aplicada em um Instituto Politécnico em Portugal, para os alunos do curso de graduação (licenciatura é o termo usado em Portugal) em Biologia e Biotecnologia. Participaram, voluntariamente, durante as aulas, dessa pesquisa 09 (nove) alunos do primeiro semestre do curso. $O$ propósito de pesquisar alunos do primeiro semestre era de buscar os conhecimentos provenientes do ensino médio e não concepções adquiridas no ensino superior.

Os sujeitos da pesquisa apresentavam idades variadas entre 18 e 24 anos, provenientes de Cabo Verde, Guiné e Portugal. Os nomes dos alunos foram ocultados e cada um era identificado por um código, para que eles tivessem segurança e tranquilidade de não serem reconhecidos e expostos. Apenas o campo de preenchimento sobre o e-mail era opcional. 
Todo o processo foi dividido em 3 (três) etapas: " 1 ' teste", o " $2^{\circ}$ teste" e o " $3^{\circ}$ teste". No primeiro teste, os alunos tiveram acesso, pelo Google Drive - Forms, a um questionário dividido em três partes: a primeira buscava as informações básicas dos sujeitos, como: código identificador, a data de nascimento, país atual, nacionalidade, nível de escolaridade e área científica que estudou no ensino secundário (médio); a segunda com as perguntas sobre Zoologia e a terceira parte de agradecimento pela participação na pesquisa.

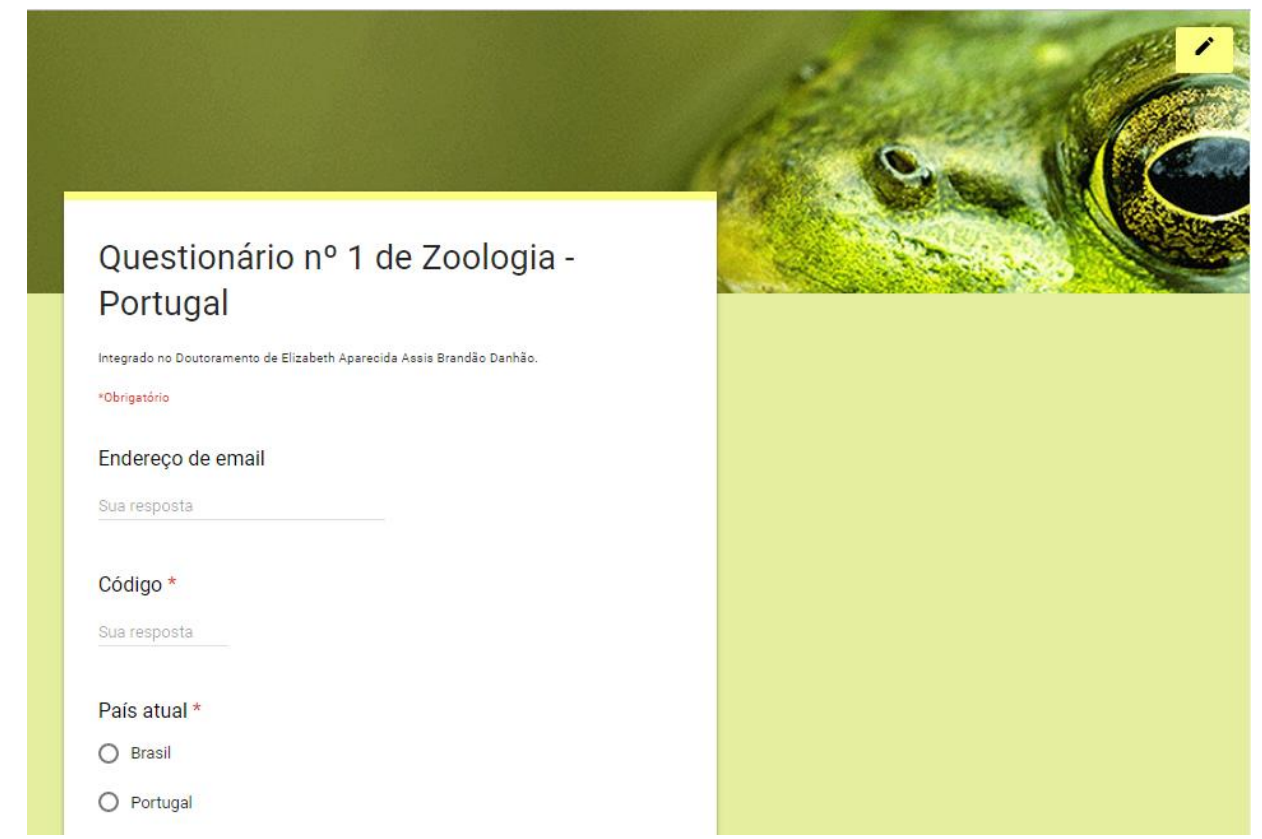

Figura 1: Print da primeira parte do questionário do $1^{\circ}$ Teste. Informações básicas para identificação dos sujeitos da pesquisa. Fonte: próprios autores.

Os links dos questionários foram disponibilizados através de um e-mail criado para esse fim. Os alunos receberam informações sobre usuário e senha para acessar um link pelos próprios celulares. Foi fornecido um link por vez, de acordo com a data das aplicações dos testes. Os questionários não eram cronometrados e sim, com tempo livre de execução.

Após o preenchimento dos dados pessoais e do código, os alunos acessaram a segunda questão que continha um texto introdutório e as 10 (dez) questões de múltipla escolha. Para iniciar a sessão introduzimos um texto e uma imagem com uma curiosidade sobre Zoologia. No $1^{\circ}$ teste a curiosidade era sobre um fóssil de formiga gigante. A ideia do texto introdutório era apenas ilustrativo, a título de curiosidade, para estimular os alunos a leitura e iniciar os estudos sobre Zoologia. O texto não estava presente no objeto digital de aprendizagem e nem nas questões analisadas.

As 10 (dez) questões de múltipla escolha apresentavam de 04 (quatro) - ("a","b","c" e "d") a 05 (cinco) alternativas ("a","b","c","d" e "e"). Como os conteúdos de zoologia são muito amplos, em cada questionário colocamos 05 (cinco) questões sobre invertebrados e 05 (cinco) questões sobre vertebrados. As questões buscavam conhecimentos básicos de zoologia, como estruturas básicas, anatomia, estrutura celular, biologia individual ou coletiva dos seres vivos invertebrados e vertebrados. Para finalizar o $1^{\circ}$ teste, a terceira $\mathrm{e}$ última sessão, constavam agradecimentos pela participação voluntária. 
As perguntas foram baseadas e adaptadas de questões de vestibulares e contemplavam os conteúdos presentes no site do Planetabio, objeto digital de aprendizagem escolhido para essa análise. Em todas as questões colocamos imagens e/ou símbolos, palavras-chave, que os alunos poderiam encontrar e associar no objeto digital.

\section{Questionário $n^{\circ} 1$ de Zoologia - Portugal}

Diga o que sabe acerca deste Reino, respondendo às 10 (dez) questões seguintes. Lembrese que existe apenas uma resposta correta para cada uma das questões de escolha múltipla. Estas questões abordam conceitos de Zoologia, com ênfase em Invertebrados e Vertebrados.

1) O corpo das esponjas é revestido externamente por células de formato achatado. Qual é o nome dessas células? *

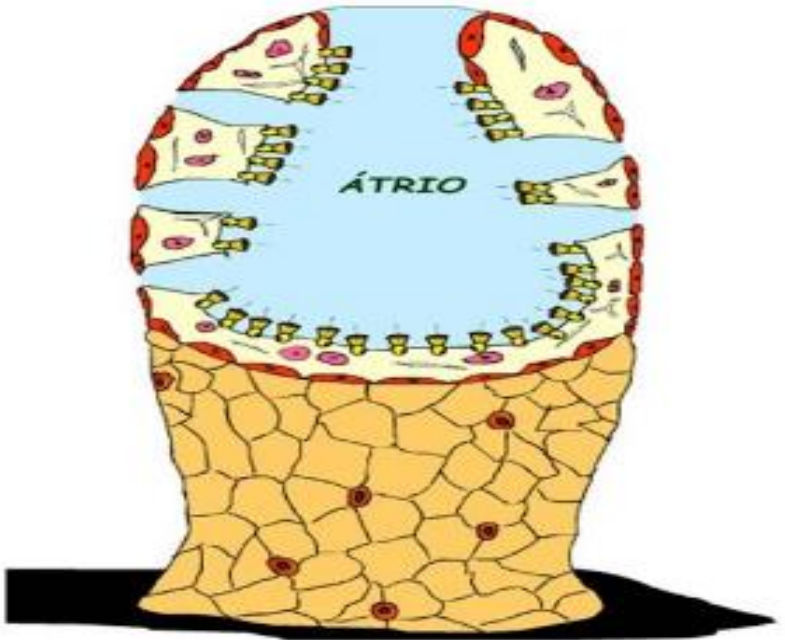

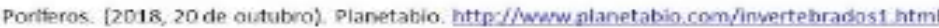

a) Ósculos.

b) Coanócitos.

c) Porócitos

d) Pinacócitos.

e) Cnidoblastos.

Figura 2: Print do questionário do 1ํ teste, disponibilizado para os alunos através do Google Drive-Forms. Fonte: próprios autores.

Após uma semana do $1^{\circ}$ teste, os alunos foram submetidos à segunda etapa da metodologia, o " $2^{\circ}$ teste". Nesta fase, os alunos, interagiram durante uma hora com o site do Planetabio, nas abas específicas de pesquisa sobre Zoologia dos Invertebrados e dos Vertebrados, explorando-as livremente. 


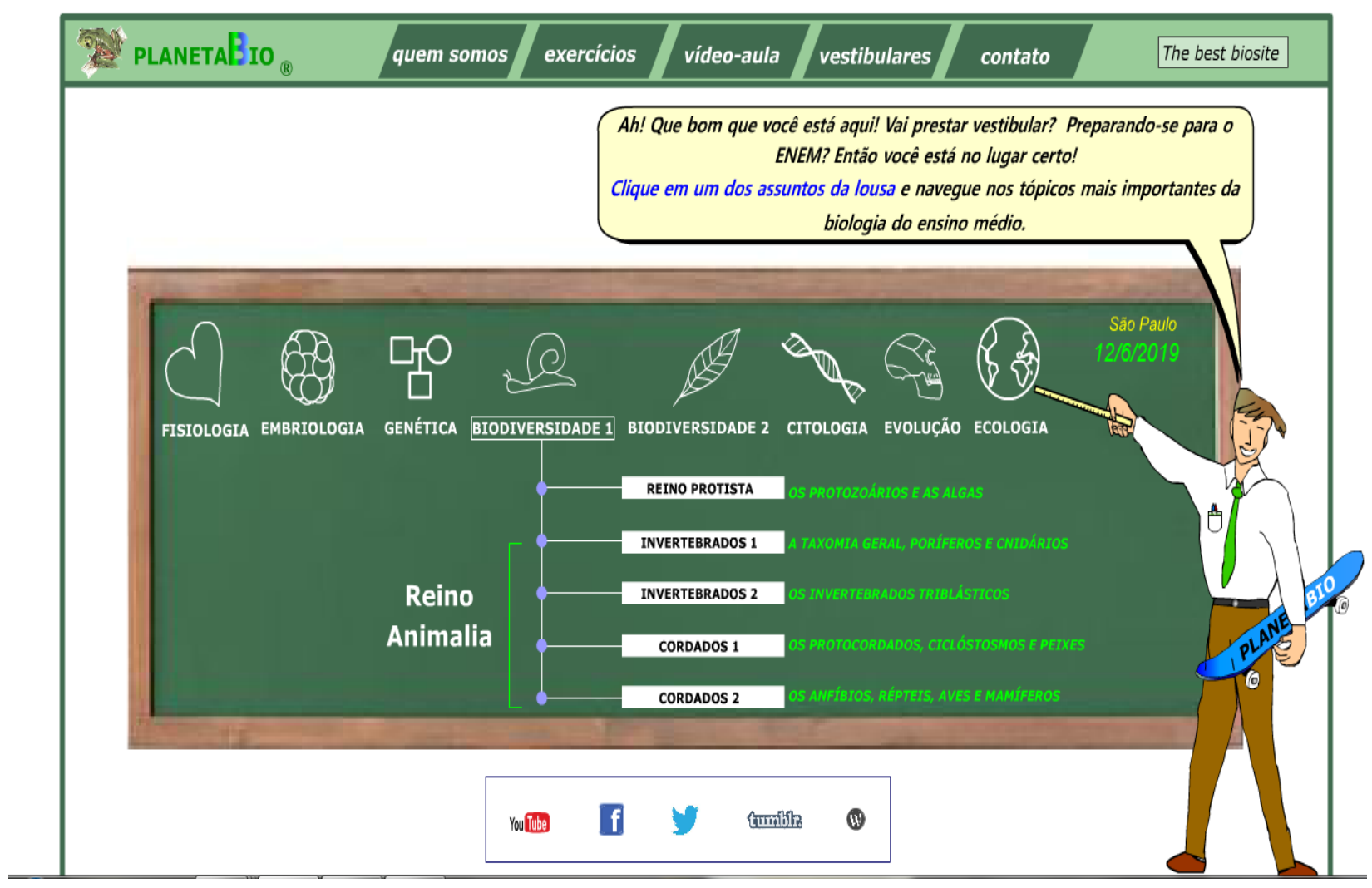

Figura 3: Layout do site Plabetabio.com as abas do Reino Animalia visíveis. Fonte: Disponível em:< http://www.planetabio.com/planetabio.html>. Acesso em 12 jun 2019.

Após 01 (uma) hora de exploração, os alunos foram direcionados ao $2^{\circ}$ teste. Os professores presentes, apenas acompanharam o processo, orientando os alunos quanto aos endereços de acesso, tempo de utilização e preenchimento dos dados pessoais. Os alunos receberam informações que não poderiam tirar dúvidas quanto aos conteúdos e quanto às perguntas nos três (3) testes.

O 2ํㅗㄴ teste era também composto de 10 (dez) questões de múltipla escolha, contendo assuntos específicos de Zoologia dos invertebrados e dos vertebrados, como sistemas e ciclos de vida, biologia individual e/ou coletiva, características exclusivas e peculiaridades. Em todas as questões colocamos símbolos ou imagens encontradas no site Planetabio, para que os alunos pudessem, de forma consciente ou inconsciente, relacionar os conhecimentos prévios, os conteúdos aprendidos com os assuntos a serem respondidos. 
Diga o que sabe acerca deste Reino, respondendo às 10 (dez) questões seguintes. Lembrese que existe apenas uma resposta correta para cada uma das questöes de escolha múltipla. Estas questões abordam conceitos de Zoologia, com ênfase em Invertebrados e

Vertebrados.

1) A reprodução dos poríferos pode ocorrer de maneira assexuada ou sexuada. Na reprodução assexuada ocorre a formação de estruturas resistentes, revestidas por espículas, que abrigam amebócitos, formando uma expansão que dará origem a outra esponja. Essa estrutura pode desprender-se ou não do indivíduo que a gera. A esse tipo de reprodução damos o nome de: *
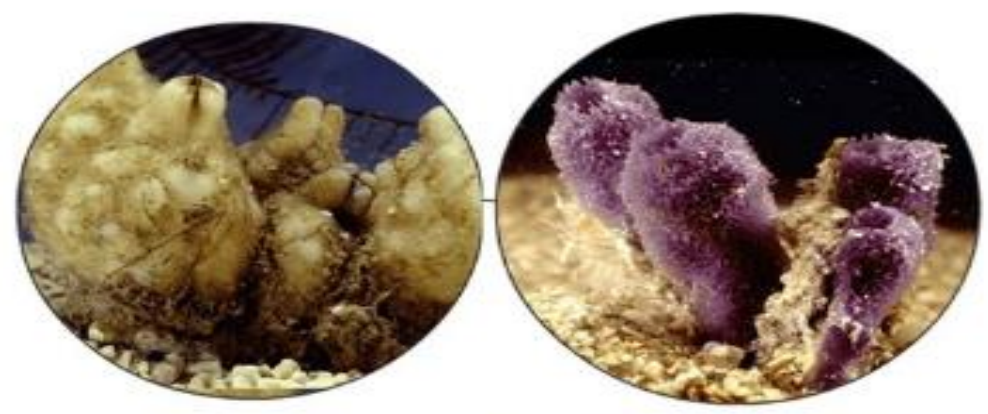

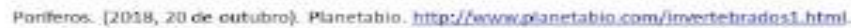
a) Gemulação.
b) Estrobilização
c) Regeneração.
d) Desenvolvimento direto.
e) Desenvolvimento indireto.

Figura 4: Print do $2^{\circ}$ teste disponibilizado aos alunos pelo Google Drive Forms. Fonte: próprios autores.

A etapa seguinte aconteceu 15 (quinze) dias depois da interação com o objeto digital de aprendizagem Planetabio. Esse tempo foi estimado e baseado nas disponibilidades de aplicação dos professores e em um intervalo mínimo para assimilação e absorção dos assuntos explorados.

No $3^{\circ}$ teste, os alunos foram submetidos a responderem 10 (dez) novas questões de múltipla escolha. $\mathrm{O}$ foco das questões, com conteúdo de zoologia dos invertebrados e dos vertebrados, era a aplicação dos conteúdos assimilados, a relação desses conteúdos com os seres humanos e a sondagem da utilização dos conhecimentos adquiridos com problemas e as situações do cotidiano. 


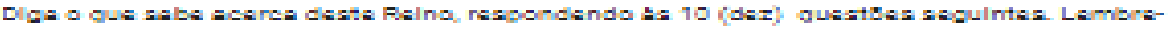

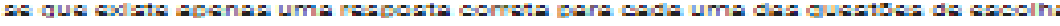

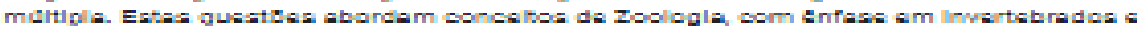
vartazrase.

1) Antes da descoberta do pläatico, a:a eaponjas de banho utilizadas na higiene peasoal eram obtidas a partir de animais marinhos pertencentes ao filo Porifera. Em relaciäo aos animais desas Filo e de acondo oom as auss caracteristicas, podemos afirmar que: D Stä invertebrados aquáticos filtradores, de corpo esponjoso e de estrutura simplea, sem tecidos ou brgäba diferenciados, nem aistema nervoso ll) Apresentarn inumerosos poros laterais e na regiäo superior do corpo. uma ünica abertura para a entrada do alimento e da água, denominada de baculo: III) Apreaentam digestä extracelular na espongiocele, que ocorre por meio de enzimas produzidas pelos nematocistos; IV) Apreaentam digesta intracelular, que ocorre no interior doa coanbcitos e doa amebocitos; Vy Apresentam cinculaçio de água, facilitada por meio de células especiais flageladas. denominadas de coanbcitos. Assinale a opgäo que integra afirmacoses corretas.

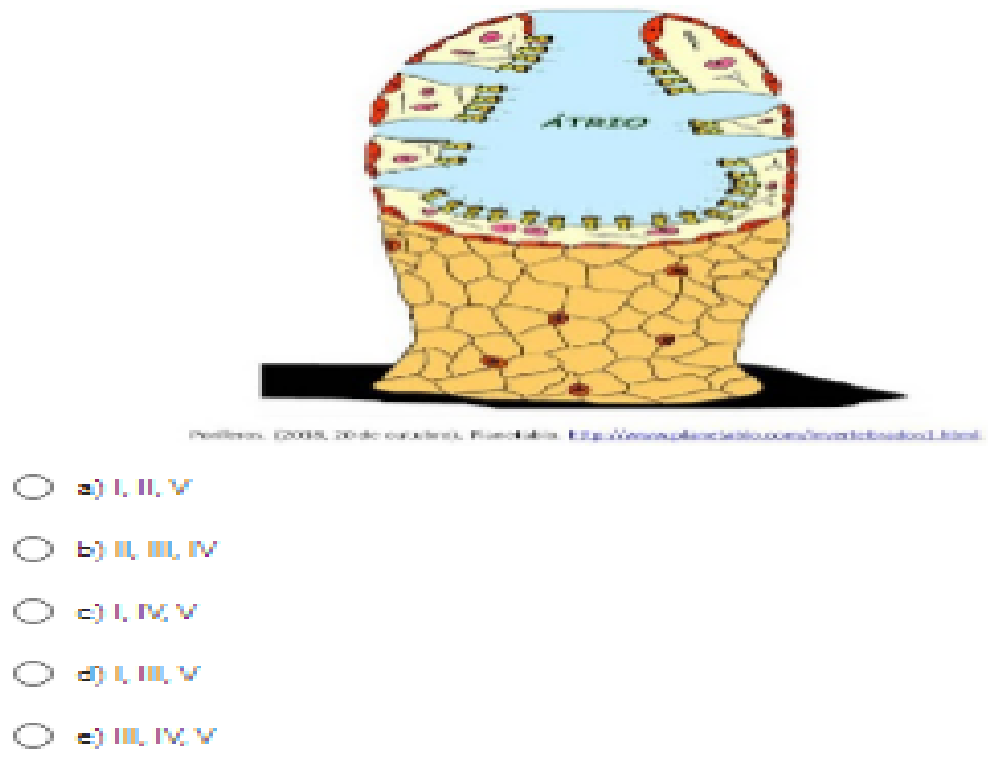

Figura 5: Print do 3o teste de Zoologia. Disponibilizado para os alunos através do Google Drive Forms. Fonte: próprios autores

\section{Analises e resultados}

Os resultados foram analisados de forma quantitativa simples, ou seja, analisamos o número de acertos por aluno e por teste. Não realizamos análises estatísticas mais minuciosas, devido ao pequeno número de dados. A partir daí, realizamos algumas comparações entre os resultados. Na figura 6 , temos os números de acertos de cada aluno nos 3 testes, ilustrados através de uma tabela com valores detalhados e um gráfico evolutivo do total de acertos de todos os alunos. 


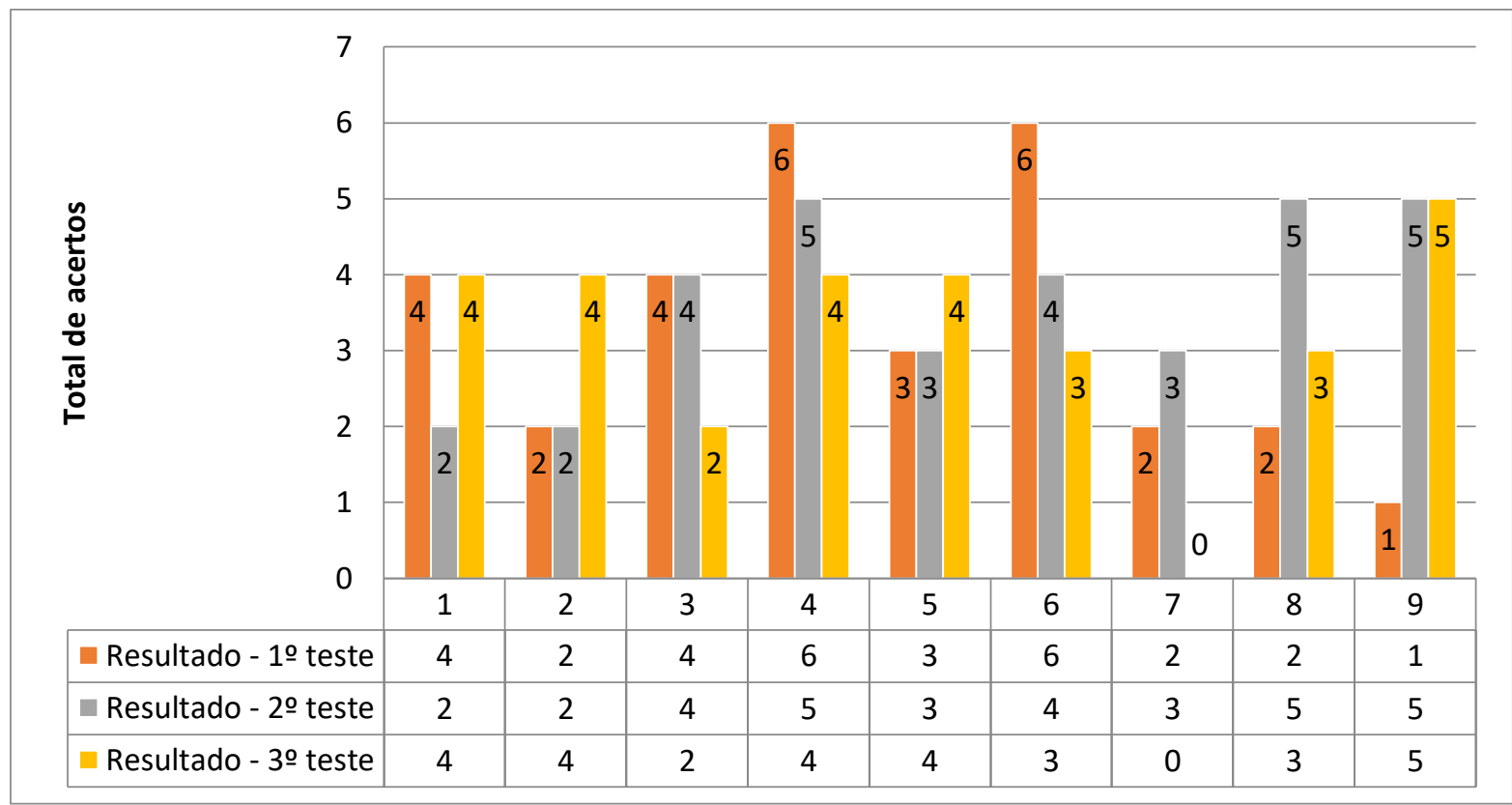

Figura 6: Gráfico ilustrativo dos resultados dos testes. Fonte: próprios autores.

A figura 6 nos transmite uma visão geral dos dados coletados dos alunos nos 03 (três) testes de Zoologia. Através dessa informação podemos realizar outras análises, como a média da sala nos 03 (três) testes, a evolução da pontuação por aluno e a quantidade de alunos que modificaram suas pontuações nos comparativos do $1^{\circ}$ teste para o $2^{\circ}$ teste, do $2^{\circ}$ teste para o $3^{\circ}$ teste e do $1^{\circ}$ para $03^{\circ}$ teste.

Se considerarmos as médias da turma por teste, temos no $1^{\circ}$ teste uma média equivalente a 3,3 pontos. No segundo teste, temos uma média de 3,7 pontos e no $3^{\circ}$ teste temos uma média de 3,2 pontos. Com uma análise simples podemos perceber que a média da sala foi maior após a utilização do objeto digital de aprendizagem Planetabio, pois ocorreu um aumento na média da turma de 3,3 para 3,7.

O gráfico abaixo nos ilustra a evolução dos alunos em comparativo dos 03 (três) testes. Nele podemos observar o número de alunos que aumentaram, os que diminuíram e os que mantiveram as notas por turma e por teste.

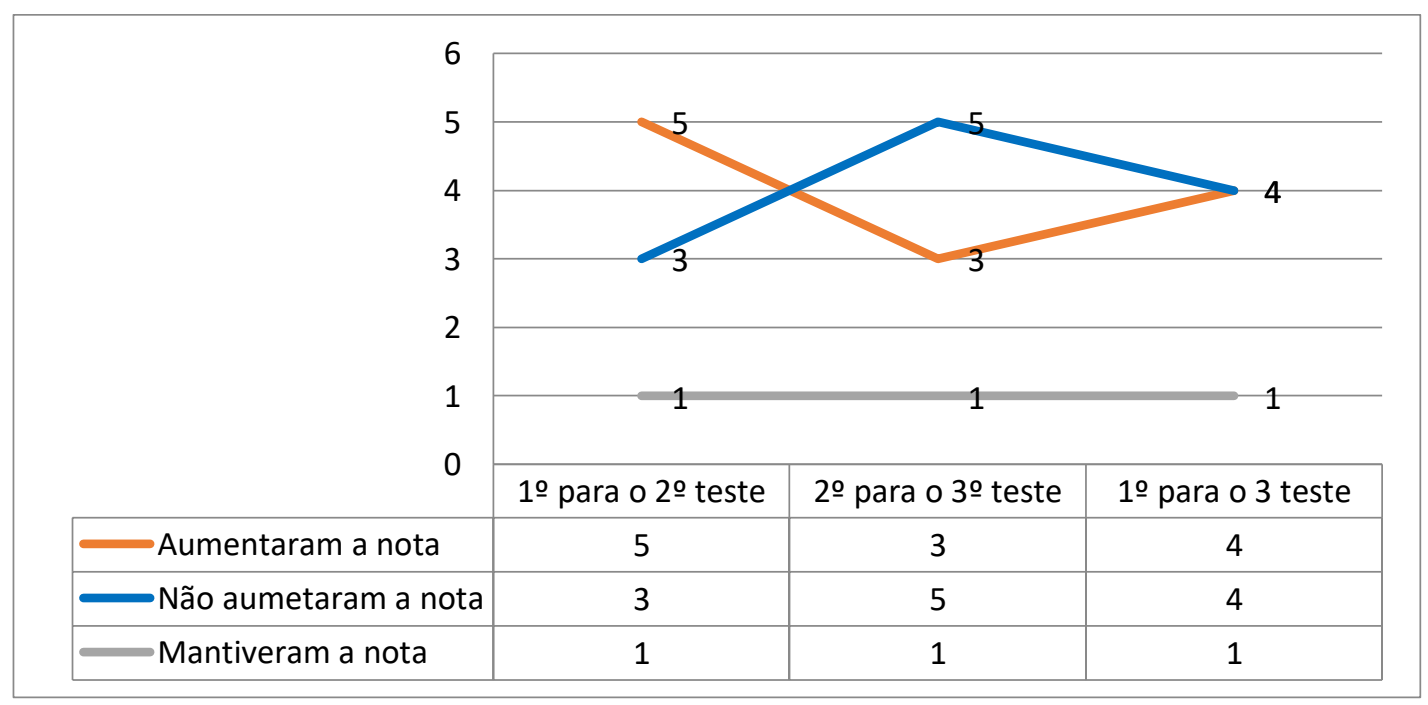


Figura 7: Gráfico ilustrativo do Desempenho dos alunos nos 3 testes de Zoologia. Fonte: próprios autores

Portanto, analisando os resultados de forma quantitativa temos 05 (cinco) alunos que mantiveram a nota entre $01^{\circ}$ e $02^{\circ}$ teste, 03 (três) que diminuíram e 01 (um) que manteve o mesmo número de acertos. Comparando os resultados do segundo teste para o 3ํㅡㄴ teste, temos: 03 (três) alunos que aumentaram o número de acertos, 05 (cinco) alunos diminuíram e 01 (um) aluno manteve o mesmo número de acertos. E se compararmos os resultados do 1을 para o $3^{\circ}$ teste, temos: 04 (quatro) alunos com aumento de acertos, 04 (quatro) alunos com diminuição de acertos e 01 (um) aluno que manteve a mesma quantidade de acertos.

\section{Considerações Finais}

Os resultados nos mostram que nas médias por turma, os alunos apresentaram melhor desempenho no $2^{\circ}$ teste. Isso pode ser um indicativo de influência do uso do objeto digital de aprendizagem Planetabio, pois a média da sala aumentou no $2^{\circ}$ teste que foi realizado imediatamente após a exploração do site.

Nos comparativos entre os testes temos um aumento de acertos considerável entre o $1^{\circ}$ e o $2^{\circ}$ teste. Um total de 05 (cinco) alunos com aumento de acertos neste intervalo. No intervalo do $2^{\circ}$ para $03^{\circ}$ teste temos uma diminuição do número de acertos para 05 (cinco) alunos. E se analisamos os valores de $1^{\circ}$ para $3^{\circ}$ teste, observamos que o número de alunos que aumentaram os acertos é igual ao número de alunos que diminuíram os acertos, ou seja, 04 (quatro) alunos aumentaram o número de acertos e 04 (quatro) alunos diminuíram esse número no mesmo intervalo de tempo e testes.

Quando analisamos de forma geral o maior número de acertos, ou seja, o melhor desempenho dos alunos, percebemos que ele ocorre após a utilização do objeto digital de aprendizagem e isso pode representar uma influência do objeto digital na realização dos testes e até mesmo no processo de ensino e aprendizagem.

Sabemos que para a conclusão final ainda serão necessários outras análises e outros testes mais minuciosos. Talvez com um valor de indivíduos (n) participantes maior, poderemos comparar mais dados e realizar mais análises, inclusive estatísticos. Portanto, essa pesquisa é promissora para novas propostas e análises.

\section{Referências}

BETTIO, R. W., MARTINS, A. M. Objetos de Aprendizagem: Um novo modelo direcionado ao Ensino a Distância. 2005. Disponível em <http://www.portaleducacao.com.br/educacao/artigos/2399/objetos de aprendizagem um novo modelo direcionado ao ensino a distancia> Acesso em 10 jun 2019.

BITTAR, M. Possibilidade e dificuldades da incorporação do uso de softwares na aprendizagem da matemática. In: Seminário Internacional de Pesquisa em Educação Matemática (SIPEM), 3, Águas de Lindóia - São Paulo. G06 - Educação Matemática novas tecnologias e educação à distância. Anais em CD. 2006. 
BITTAR, M.. Informática na educação e formação de professores no Brasil. Revista Série - Estudos, n. 10, 2013.

BRASIL. Ministério da Educação. Secretaria de Educação a Distância. Objetos de aprendizagem: uma proposta de recurso pedagógico. Organização: Carmem Lúcia Prata, Anna Christina A. de Azevedo Nascimento. - Brasília: MEC, SEED, 2007.

MOTTA A.; ANGOTTI, J. A. P. Avaliação discente de um Curso de Tecnologia em Gestão Pública à luz da Teoria da Interação a Distância. Revista Brasileira de Ensino de Ciência e Tecnologia. v. 4, n. 1, 2011. Disponível em:<https://periodicos.utfpr.edu.br/rbect/article/view/609/653>. Acesso em: 10 jun 2019.

NESBIT, J. C., BELFER, K. and LEACOCK, T. "Learning object review instrument (LORI)". E-learning research and assessment network. 2003.

PLANETABIO. Site Planetabio. Disponível em:<http://www.planetabio.com.br/>. Acesso em 10 jn 2019.

SCHEUNEMANN, C. M. B.; LOPES, P. T. C. Análise de um hipertexto digital no ensino de ciências: percepções de alunos do ensino fundamental. Revista de Ensino de Ciências e Matemática, v. 9, n. 5, p. 14-35, 2018.

TEDESCO, J. C.; BERLINER, C. Educação e novas tecnologias: esperança ou incerteza?. Cortez, 2004.

VYGOTSKY, L. A formação social da mente: o desenvolvimento dos processos psicológicos superiores. 5 ed. São Paulo: Martins Fontes. 1994.

WILEY, D. A. Conecting learning objects to instructional theory: A definition, a methaphor anda a taxonomy. The Instructional Use of Learning Objets. Wiley, D. (Ed.) 2001. Disponível em:<http://www.reusabilility.org/read/chapters/wiley.doc>. Acesso em 10 jun 2019. 